Nooh Taha Nasif

AL-Nakuha University College, Baghdad, Iraq

\title{
METHODS OF DATA AGGREGATION FOR TRAFFIC REDUCING IN SG COMMUTATION NETWORKS FOR SECURITY AND SG DATA POLICY
}

The transformation of the outdated electrical grid into the Smart Grid (SG), which provides a two-way information flow between the various SG components, creates many problems in designing and developing efficient $S G$ communication infrastructures for connecting various $S G$ components. In addition to the currently used core networks and protocols, new wired and wireless approaches are planned for various $S G$ components and applications deployment. The proposed SG communications infrastructure will have many interconnected systems with a variety of capabilities and management to provide end-to-end services to users, as well as among intelligent devices.

Keywords: intelligent transport systems, wireless sensor networks, wireless sensors, road monitoring.

\section{Introduction}

Problem statement. Despite the growing interest to identifying the SG communication network and possible SG applications, specification of the studies in the network protocol have not yet been developed. This article has revised each la TCP / IP protocol stack layer, which was basically designed for a wired network. Their performance has been optimized in the communication network with the extended measurement infrastructure (AMI) based on IEEE 802.11. Improvements of a multilevel and inter-level protocol are proposed. At the application level a temporary tree-based timetable and planning on the basis of multiple access with time multiplexing for reducing of the high competition level scheduling were proposed.

\section{Problem state}

Interest to the $\mathrm{SG}$ identification communication network has been growing during the latest few years. [1], in particular for the application of the amplified measurement infrastructure (AMI). AMI is considered to be one of the six key priorities for SG [2]. It is designed for collection, measurement and energy consumption data analyzing by consumers through smart meters (SM) to pave the way for dynamic and automatic pricing for electricity. In AMI household appliances of SM, SMs report about the data aggregation point, such as a gateway in a distribution substation and then the aggregation point transmits these reports to the service center. Taking into consideration AMI diapason, SG AMI communication network will be multi-level [1], which consists of Home Area Network (HAN), neighborhood networks (NAN) worldwide-area network (WAN). HAN is located in the customer's domain and provides access to home appliances. NAN binds SMs with local access points, and WAN provides connection between local access points to the service center. Each level can use various communication technologies (for example, wireless, wired) [1], various protocol standards (for example, open standards, own) and may belong to different entities (for example, consumer, utility company, cellular provider). The decision which communication technologies will be adopted depends on various factors, such as network characteristics, cost, geographic needs, tasks and types of applications and services for consumers [3].

Recently, wireless network technologies have been introduced for AMI large-scale communication networks [4]. Among the parameters of the wireless network IEEE 802.11s [5] is one of the viable options of the NAN wireless network for AMI. IEEE 802.11s expands IEEE 802.11 standard, adding the self-encrypting network capabilities of a multi-core network to the medium access control layer (MAC) IEEE 802.11. Instead of using Internet-level routing, IEEE $802.11 \mathrm{~s}$ includes routing at the MAC level (i.e. multilevel approach [6]), called a hybrid wireless mesh protocol (HWMP). It also supports quality of service traffic (QoS) by including IEEE 802.11e standard [7]. However, since IEEE 802.11 s Recently approved as an amendment to the IEEE standard 802.11 in 2012, large-scale real world deployment of SG communication networks on the basis of IEEE $802.11 \mathrm{~s}$ are limited, and performance problems with increasing network diameters have not been well researched [8].

TCP/IP Protocols [9] are initially developed and optimized for wireless network. Extensive studies of showed, that TCP/IP protocols do not provide optimal production for wireless network. Wireless networks have four main characteristics, which differ them from their wireless networks [10]:

1) channel competition;

2) signal fading;

3) mobility;

4) limited power and energy. 
Although various protocol optimization enhancements, some of which may include cross-optimization have been proposed for the wireless network [11], these improved protocols may occur not sufficient when they are implemented for the SG communication network because of the specific SG reliability requirements, security and confidentiality. Although recently there have been some initiatives to improve the TCP / IP protocol for the SG wireless network, but works are limited to SG routing protocols [1], and only a few work at other TCP / IP protocol levels [12].

\section{Problem statements}

The research aims and objectives. The aim of this research - is to revise TCP/IP protocol step and propose new or improved TCP/IP protocols, which will be used in the SG communication network on the basis of IEEE $802.11 \mathrm{~s}$, when it is deployed as an AMI environment address network. Although the SG communication network based on the IEEE 802.11s is the main focus of the study, since interoperability between networks is also a very important factor for meeting SG requirements [4], the Long Term Evolution (LTE) cellular network [13] is considered as WAN for AMI application.

In particular, the study addresses the following specific problems of SG:

1) security and privacy;

2) AMI data explosion;

3) periodic scheduling of simultaneous data reports;

4) low performance of transport control protocol (TCP);

5) broadcast address resolution protocol (ARP);

6) network compatibility.

The effectiveness of all proposed approaches in the study is confirmed by extensive simulation experiments using a discrete network simulator ns3. Throughout the study, four performance indicators were used:

1. Package delivery ratio (PDR), which indicates the number of packets received in the data collector divided by the number of packets transmitted by all SM. This indicator has crucial meaning to prevent the positive impact of the proposed package delivery method.

2. Avergae end-to-end (ETE) retention of all packets on the level of application. This factor indicates average ETE retention of all packets from smart meter to the airlock or utility company.

3. Bandwidth that indicates the number of bits received at the gateway or utility company divided by the total simulation time.

4. The average collection time, which indicates the total collection time from all rounds of readings for decontamination, divided by the number of rounds during the simulation. The collection time for each round is measured as the last reading time that was received at the lock or utility company for this round, minus the earliest timeline for this round. Let $\overline{C T}$ - average collection time, $m$ - number of rounds, $N$ - quantity SM, $T x_{j i}$ - schedule $S M_{j}$ to send your report to the round $i, R x_{j i}$ - time of report receipt, send from $S M_{j}$ at the gateway for the round $i$, where $i=1,2, \ldots, m$ and $j=1,2, \ldots, N$. The average collection time corresponds (1):

$$
\overline{C T}=\frac{\sum_{i=1}^{m}\left(\max _{1 \leq j \leq N}\left(R x_{j i}\right)-\min _{1 \leq j \leq N}\left(T x_{j i}\right)\right)}{m} .
$$

PDR, ETE delay and data collection are measured on the application level, since the purpose is to measure all delays, because the packet is sent to SM. However, throughput is measured at the transport level, because good performance (i.e., application layer throughput) eliminates the overhead of the protocol.

On the fig. 1 a communication network is shown SG AMI, investigated in the study. Each SM, which is set in each house is equipped with a radio IEEE 802.11 s. A large number of SM in the surroundings are grouped in NAN. Each NAN is headed by a gateway node, which can optionally transfer data collected from SMs to a utility company via the LTE network

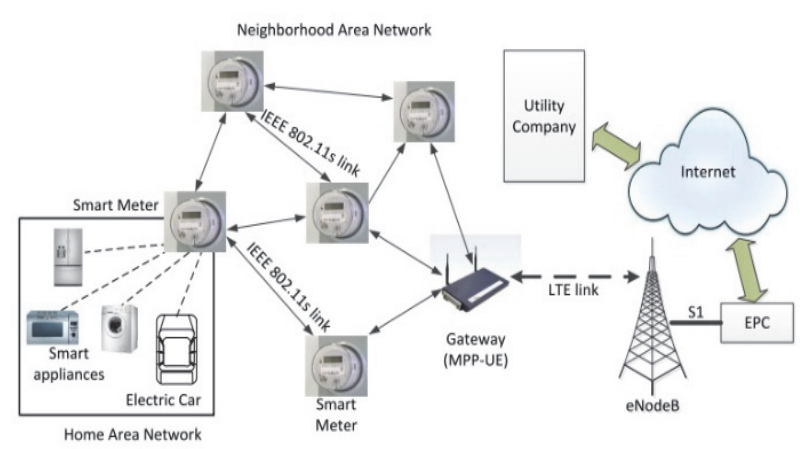

Fig. 1. Communication network SG AMI, investigated in the study

In this communication network SG AMI a gateway with two interfaces is used, IEEE 802.11s interface and LTE interface to support bi-directional traffic between network layers. For NAN on the basis of IEEE 803.11 the gateway serves as a Mesh Portal Point (MPP) and the root node for routing the Hybrid Wireless Network Protocol (HWMP), the default path selection protocol IEEE 802.11s.

Let each SM be always available through the gateway, and each SM can achieve gateway in multihop mode via another SM. For LTE network this gateway serves as user equipment (UE) and can connect with communal company via the base station (i.e. ENB) and Evolved Packet Core (EPC), which serves as LTE gateway for external network (i.e. Internet). 


\section{Basic Definitions}

Here the main concepts and definitions associated with the AMI hybrid network and TCP / IP protocols, in particular, the ARP and TCP protocols are present. In addition to this, the homomorphic cryptosystem is also explained, which is very important for confidential data aggregating.

IEEE $802.11 \mathrm{~s}$ - is an alteration to the standard IEEE 802.11 , providing the possibility of multithreading for wireless local area networks. This standard covers various functions, such as network discovery, peering, security, selection and redirection of the network path. Nodes in IEEE 802.11s WMN are given names, based on their roles. All mesh routers are Mesh Points (MP) and can provide connection at the data link layer between other MPs. If MP also provides обеспечивает connection to another network, such as Internet or wire local network, it is called Mesh Portal Point (MPP). MP becomes Mesh (MAP), if it connects wireless clients (for example, Mesh Station (Mesh STA)) to the Mesh network. On the fig. 2 IEEE $802.11 \mathrm{~s}$ name agreement is shown.

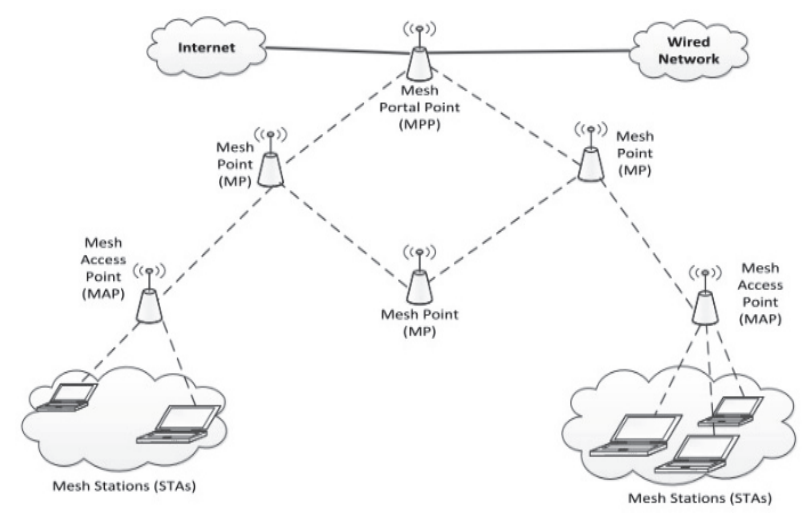

Fig. 2. IEEE $802.11 \mathrm{~s}$ architecture components

In addition to the previously defined authentication methods, IEEE $802.11 \mathrm{~s}$ accepted a protocol for the simultaneous authentication of two arbitrary peers, called simultaneous authentication of equals (SAE) [5]. In order to achieve authentication and key negotiation for $\mathrm{SAE}$, a common password and a set of domain required parameters, either from finite field cryptography (FFC) or elliptical cryptography curve (ECC). As the name implies, parties, which are participating in the exchange are equal, each party can initiate protocol and should not be a direct neighbor. Initiator (i.e. a node, initiating protocol) - this is the one that first discovers its neighbor.

LTE, which is related to E-UTRAN (Evolved Universal Terrestrial Radio Access Network), consists of user devices (EU) and base stations, called the extended node B (eNB). LTE connects to a core network with multiple access based on IP, named Evolved Packet Core (EPC). Together these two systems are collectively called Evolved Packet System (EPS). EPC bears responsibility for providence of general control for users equipment and carriers installation. EPC uses separate components for the control plane and the user plane. Carrier in LTE network mainly presents a set of network parameters, which determine the process of IP-traffic processing via LTE network. As shown on Fig.3, for IPtraffic delivery of downlink to the corresponding UE, for example, IP- packet is encapsulated using the protocol, specific for EPS (for example, EPS carrier), and is tunneled from P-GW to a correspondent eNB using a tunneling general packet radio service (GPRS) for the user's plane (GTP-U).

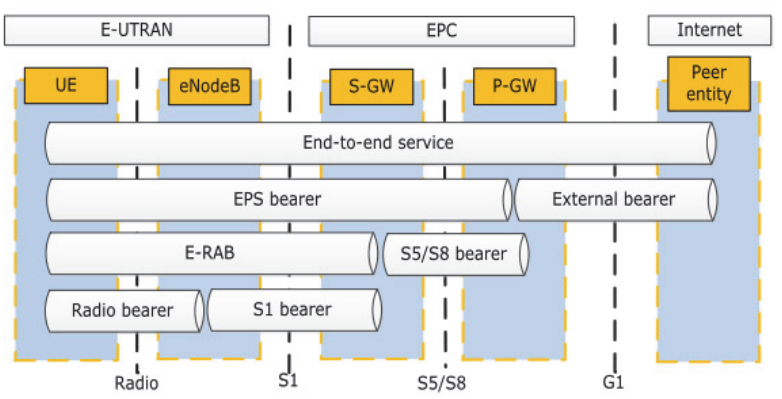

Fig. 3. Bearer Service Architecture EPS

Each node in the network on the basis of IP protocol is recognized by its IP address. However, whenever an Ethernet frame is sent from one node to another on the same network, the physical address (i.e., the MAC address) determines to which interface the frame is intended but not to the IP address. ARP provides IP-MAC address mapping. Each node supports a local ARP table to store these mappings. TCP is a window-based transport layer protocol that provides reliable connectionoriented data delivery. TCP uses sequence numbers to transfer data by numbering each data byte with a unique sequence number. Then TCP packs the data into a data segment, places the serial number of the first byte of the data segment, and passes it to the destination.

\section{Data Aggregation Modeling}

\subsection{Performance indicators for efficiency assessment}

A Java-based application was created to model data aggregation that preserves confidentiality. The goal is to assess the effectiveness of preserving homomorphic data that maintains confidentiality while at the same time being able to resist or detect the aforementioned attacks. This approach is presented as ETE-H in graphs and tables. The performance of ETE-H is compared with two other protocols:

1. HBH (HBH-A) Aggregation: in general HBH-A decrypts the data, performs aggregation in plaintext, and encrypts the aggregated data before it is searched. Therefore, it provides data to the intermediate nodes. To ensure the privacy of users, aliases are used instead of 
real identifiers. Aliases are associated with SM identifiers, but this association is known only to the receiver node, as it was done in [14]. As a result, even if the data is exposed to intermediate nodes, they cannot be associated with a real identifier.

2. $\mathrm{HBH}(\mathrm{HBH}-\mathrm{C})$ Concatenation. Another alternative to homomorphic encoding is to concatenate encrypted packets at intermediate nodes and send the concatenated packet to the upper level, as used in [15]. This is somewhat similar to the homomorphic encryption of ETE, but there is no operation on the packets. They simply concatenate and a larger package is created. Nal packet decrypts and the aggregation function is performed on the receiver node. For performance evaluation, the following performance indicators were used:

ETE Retention: is time, passed between the nodereceiver, which searches for the query and receives the average value. It is assumed that the time taken to authenticate the source is much less than the arithmetic operation, and it can be ignored when calculating the ETE delay. Moreover, this authentication process has the same effect as ETE-H, HBH-A or HBH-C.

The size of encrypted data: this metric measures the average message generated from the leaf nodes and aggregator nodes in bits. Message sizes affect the number of bits / packets required to transmit them.

Four experiments were conducted to observe the effect of the following parameters on the ETE delay and data size for ETE-H, HBH-A and HBH-C:1) key size;

2) depth of tree;

3) total number of aggregators per level;

4) effect of the algorithm for multiplication by homomorphic encryption.

The following parameters remained constant during the experiments: the network topology has $36 \mathrm{SM}$, the minimum communication delay between nodes at different depth levels is $50 \mathrm{~ms}$ and the data size of power consumption is 16 bits. The receiver generates 2000 requests to collect data on energy consumption. In addition to the key size experiments, 64-bit keys were used for all other experiments. In the experiment 1 twolevel network topology with two aggregators at each level were used. Each aggregator has $8 \mathrm{SM}$ and $9 \mathrm{SM}$ at level one and two, respectively. The experiment used a balanced network tree. The experiment began with a network with depth 1, 2 aggregators and 17 leaf nodes for the aggregator. Then the depth of the tree was increased for a unit, SM quantity was supported on the aggregator as 2 for each level and experiments should be continued until tree 5 depth achieved.

5. For experiment 3 SMs quantity for a level was changed, and depth remained constant. Experiment 4 was conducted at the receiving node, only assuming, that 36 SMs Receive messages at the receiving node in any configuration in the Table. 1 configuration of network topology and key size are given.
Table 1

Network topology contours and key size

for experiments

\begin{tabular}{|c|c|c|c|c|c|}
\hline \multirow[b]{2}{*}{$\begin{array}{c}\text { Experiment } \\
\text { Type }\end{array}$} & \multicolumn{4}{|c|}{ Network Topology Configuration } & \multirow{2}{*}{$\begin{array}{c}\text { Key } \\
\text { size } \\
\text { (bits) }\end{array}$} \\
\hline & $\begin{array}{l}\text { tree } \\
\text { depth }\end{array}$ & $\begin{array}{c}\text { \#agg. Per } \\
\text { level }\end{array}$ & $\begin{array}{c}\text { \#SMs per } \\
\text { agg }\end{array}$ & SMs P & \\
\hline Exp. 1 & 2 & 2 & $8 / 9$ & 36 & varie \\
\hline Exp. 2 & $1-5$ & 2 & varie & 36 & 64 \\
\hline Exp. 3 & 1 & $2-10$ & varies & 36 & 64 \\
\hline
\end{tabular}

\subsection{Results of the experiment and} discussion

\subsubsection{Experiment 1: The effect of key size}

The effects of using different key sizes in conjunction with the delay and data size are shown on the Fig. 4 and in Table. 2. Several observations can be made of these results.

Table 2

Comparing data sizes for different key sizes, $\mathrm{SM}=$ Smart Meter, $\mathrm{AGG}=$ Aggregator

\begin{tabular}{|c|c|c|c|c|c|c|c|c|c|}
\hline \multirow{2}{*}{$\begin{array}{c}\text { Key } \\
\text { size }\end{array}$} & \multicolumn{6}{|c|}{ average encrypted message size (in bits) } \\
\cline { 2 - 10 } (bits) & SM & AGG & $\%$ & SM & AGG & $\%$ & SM & AGG & $\%$ \\
\hline 64 & 125.2 & 1746.0 & 1295 & 125.4 & 125.4 & 0 & 125.3 & 1753.8 & 1300 \\
\hline 128 & 253.2 & 3538.2 & 1297 & 253.4 & 253.4 & 0 & 253.5 & 3549.5 & 1300 \\
\hline 256 & 509.8 & 7130.9 & 1299 & 509.0 & 509.0 & 0 & 509.3 & 7130.5 & 1300 \\
\hline 512 & 1021.7 & 14296.7 & 1299 & 1021.2 & 1021.2 & 0 & 1021.2 & 14296.71 & 1300 \\
\hline 1024 & 2045.628632 .3 & 1300 & 2045.32045 .3 & 0 & 2045.3 & 28634.3 & 1300 \\
\hline
\end{tabular}

While a larger key size can provide better protection, this is due to an exponential increase in the delay for all three approaches, as shown on the Fig. 4. HBH-C has a higher ETE delay than ETE-H and HBH-A, which have a similar delay for the specified key size. They provide a reduction of $30 \%$ compared to $\mathrm{HBH}-\mathrm{C}$ by $16-$ $40 \%$. Increasing the size of the key, which is 2 times, provides a linear increase in the average size of the encrypted SM message and aggregators by the same factor as in the Table 2.

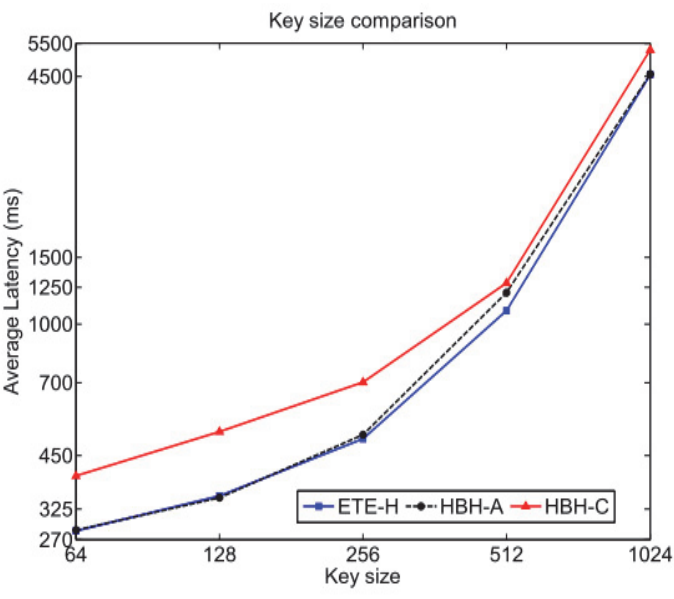

Fig. 4. Effect of the key size on the interface 
The results show, that both ETE-H and HBH-C have a similar percentage increase, even if they have different operations. This can be explained by the fact that homomorphic encryption eventually generates a new packet, which size is the total number of bits in both packets. This also applies to concatenation when combining two packets. There can be only some additional information bits that are not a significant increase. There is no increase in the data size in HBH-A, since before the aggregation is performed on intermediate SMs, received packets are decrypted first.

Taking into consideration the fact, that the HBH-A approach does not increase the message size, it is enough interesting to see, that ETE-H provides a similar ETE delay. Similarly as the approach latency ETE-H below, although the size of its message is very close to the HBH-C related. It can be explained in the following way: HBH-A performs encryption with decryptionaggregation on each aggregator, including a receiver that takes a long time, and this time should be much longer than the time taken to use ETE-H to perform a homomorphic multiplication at each node and decrypt at the receiver. Otherwise, taking into consideration that HBH-A has smaller messages for transmission and therefore the message transmission delay is much smaller, HBH-A should provide a lower ETE delay. In addition, the HBH-C has additional decryption capabilities on the receiver, where it decrypts all data messages (embedded in a large packet) before aggregation is performed. In order to show, that it is really ETE-H excellent performance justification, a separate experiment for the receiver was conducted. Expenses for $n$ encrypted messages multiplication encrypted messages, followed by decryption on the receiver were examined and compared with the decryption result $n$ of messages, and then summing them into $\mathrm{HBH}-\mathrm{C}$ for different data sizes. On the fig. 5 it is shown, that multiplication-decryption method is much more fasted, that Decryption-Sum approach in the receiver.



Fig. 5. The overhead of multiplication-decryption delay and decryption-summation at the receiver, $n-36$
This is mainly connected with the high cost of decryption compared to multiplication.

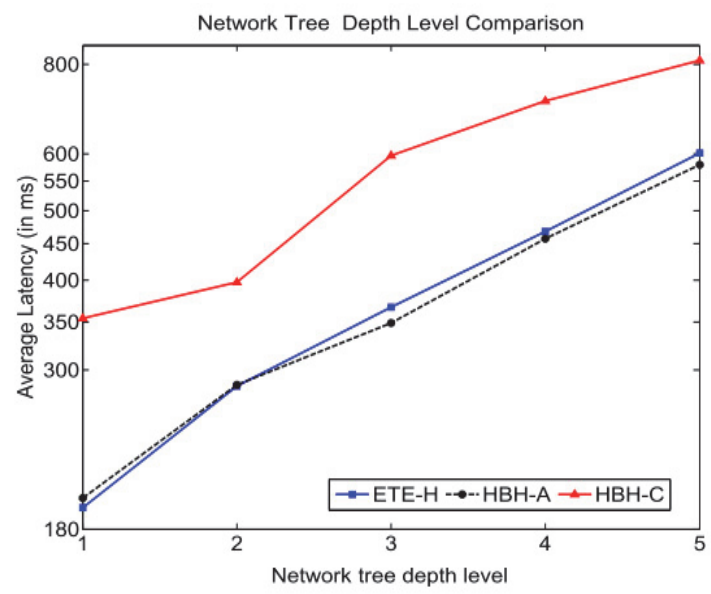

Fig. 6. Comparison of delays for different depth levels

In the previous approach, there is $n$ multiplications and 1 decryption, and in the second one $-n$ transcripts and 1 summation. This result explains why HBH-C experiencing a large delay in the receiver and why ETE-H works faster, although it performs multiplication on aggregator nodes.

\subsubsection{Experiment 2: Effect of the tree depth}

The effect of the depth of the tree on the ETE delay performance is shown in Fig. 6. ETE delay increases with depth increase in all approaches. This is due to the fact that when the receiver arrives, there will be more data transmission delay. The model in ETE delay is similar to that in Fig. 4 for the same reasons. HBH-C works $20 \%$ worse than other approaches at all depth levels. Note that the same performance ratio is supported because the total number of SMs does not change on the network. The total number of SMs affects the overhead of the receiver, which can significantly change the ETE latency. However, in terms of the message size, while the average data size generated by the aggregator nodes in the HBH-A remains constant, both ETE-H and HBH-C show a significant increase in the data size with an increase in the tree depth, as shown in the Table. 3. Therefore, ETE-H and HBH-C consume more bandwidth than HBH-A.

Table 3

Comparing data sizes with different tree network depths

\begin{tabular}{|c|c|c|c|c|c|c|c|c|c|}
\hline \multirow{2}{*}{$\begin{array}{c}\text { Tree } \\
\text { depth }\end{array}$} & \multicolumn{6}{|c|}{ average encrypted message size (in bits) } \\
\cline { 2 - 11 }$($ level) & SM & AGG & $\%$ & SM & AGG & $\%$ & SM & AGG & $\%$ \\
\hline 1 & 125.2 & 2244.3 & 1693 & 125.2 & 125.2 & $0 \%$ & 125.4 & 2257.4 & 1700 \\
\hline 2 & 125.2 & 1746.0 & 1295 & 125.4 & 125.4 & $0 \%$ & 125.3 & 1753.8 & 1300 \\
\hline 3 & 125.5 & 1500.8 & 1095 & 125.3 & 125.3 & $0 \%$ & 124.7 & 1495.9 & 1100 \\
\hline 4 & 125.6 & 1501.3 & 1096 & 125.1 & 125.1 & $0 \%$ & 125.0 & 1500.6 & 1100 \\
\hline 5 & 125.4 & 1498.9 & 1096 & 125.2 & 125.2 & $0 \%$ & 125.1 & 1501.6 & 1100 \\
\hline
\end{tabular}

Taking into consideration depth and time of tree processing, result of this section can be summarized as 
follows: the transfer time from leaf nodes to the aggregator has a small contribution to the ETE latency, since the encrypted message data size from the leaf nodes is usually small.

The transmission time from the aggregator to its ancestor node will have a significant contribution if the data size is larger. In addition, considerable processing also will take a place. The processing time on the aggregator from the highest to the lowest value is located in the following order: HBH-A, ETE-H and HBH-C, and at the receiving node-HBH-C, $\mathrm{HBH}-\mathrm{A}$ and ETE-H, respectively.

\subsubsection{Experiment 3: Influence of the aggre- gators to the tree level}

The purpose of this experiment is to analyze the effect of load propagation on more aggregators for performance.

Revising the delay, ETE, ETE-H and HBH-A work better than $\mathrm{HBH}-\mathrm{C}$ when the number of aggregators is less (Fig. 7).

As the number of aggregators increases, more operations performed at the receiver due to the increase in the number of children will be performed.

This increases processing latency for both multiplication and decryption, and therefore ETE-H and $\mathrm{HBH}-\mathrm{A}$ latency becomes similar to the delay with $\mathrm{HBH}-$ $\mathrm{C}$ as the number of aggregators increases. For HBH-C the total amount of decryption will not change, but it takes advantage of the parallelism between the increase in the number of aggregators performing the aggregation, which helps to maintain the delay.

As for the data size, the results show that as the number of aggregators increases to the tree level, the average message size generated by the aggregators decreases, as shown in the Table. 4.

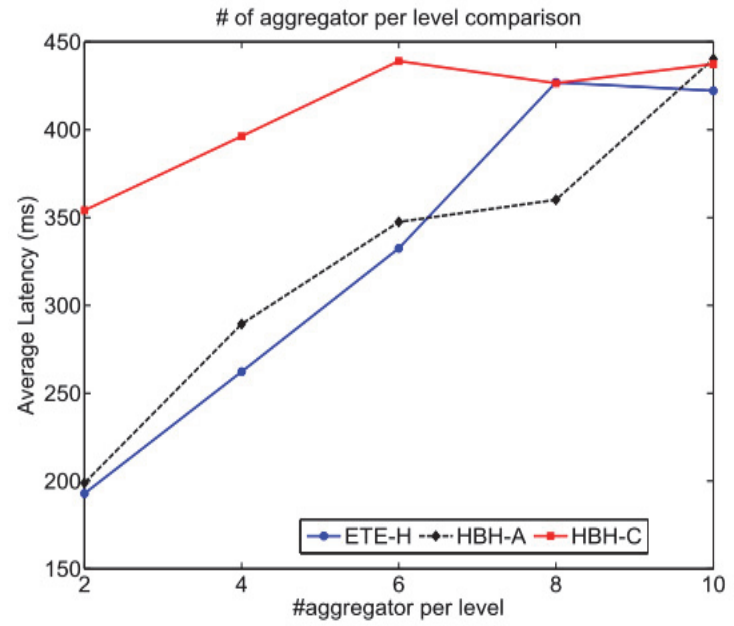

Fig. 7. Comparison of delays for different number of aggregators at tree level
Table 4

Comparison of data sizes for different number

of aggregators per level

\begin{tabular}{|c|c|c|c|c|c|c|c|c|c|}
\hline \multirow{2}{*}{$\begin{array}{c}\text { \#agg } \\
\text { per } \\
\text { level }\end{array}$} & \multicolumn{6}{|c|}{ average encrypted message size (in bits) } \\
\cline { 2 - 11 } & SM & AGG & $\%$ & SM & AGG & $\%$ & SM & AGG & $\%$ \\
\hline 2 & 125.2 & 2244.3 & 1693 & 125.2 & 125.2 & $0 \%$ & 124.8 & 2246.2 & 1700 \\
\hline 4 & 125.4 & 1124.8 & 797 & 125.3 & 125.4 & $0 \%$ & 125.2 & 1126.8 & 800 \\
\hline 6 & 125.1 & 748.4 & 498 & 125.3 & 125.3 & $0 \%$ & 125.2 & 751.4 & 500 \\
\hline 8 & 125.3 & 561.9 & 349 & 124.8 & 124.8 & $0 \%$ & 125.5 & 564.9 & 350 \\
\hline 10 & 125.4 & 450.3 & 259 & 125.0 & 125.0 & $0 \%$ & 125.7 & 452.4 & 260 \\
\hline
\end{tabular}

4.2.4 Experiment 4: Using the algorithm of different multiplication in ETE-H

In the experiments mentioned above, ETE-H uses the default Java multiplication operation. Since different computational algorithms can give different results, the purpose of this experiment is to investigate the effectiveness of the Karatsuba multiplication algorithm [16], shown in Alg. 1, compared to the default Java multiplication. When implementing the Karatsuba algorithm, the value of cutoff is used to limit the number of recursive operations.

$K-n$ is defined as the value of cutoff, which is equal to the operands bits maximum length divided by $2^{n}$. Consequently, cutoff Karatsuba-1 $(K-1)$ meaning to $K-3$ represents a half size, the size of the fourth and one eighth size of the operands bits maximum length.

Algorithm 1. kmultiply ( $X, Y$, cutoff)

1. if $X \leq$ cutoff and $Y \leq$ cutoff then return $X Y$

2. else split $X, Y$ in half $X=2^{n / 2} X_{1}+X_{2}$ $Y=2^{n / 2} Y_{1}+Y_{2}$.

3. $X_{1} X_{2}=$ kmultiply $\left(X_{1} X_{2}\right.$, cutoff $)$.

4. $X_{2} X_{2}=$ kmultiply $\left(X_{2} X_{2}\right.$, cutoff $)$.

5. $W=\operatorname{kmultiply}\left(X_{1}+X_{2}, Y_{1}+Y_{2}\right.$, cutoff $)$.

6. return $2^{n} X_{1} Y_{1}+2^{n / 2}\left(W-X_{1} Y_{1}-X_{1} Y_{2}\right)+X_{2} Y_{2}$.

On the fig. 8 it is shown, that when the data size (operand) more than (for example, 1024 byte), Karatsuba works better than the default multiplication algorithm in Java. Therefore, the algorithm can be used in the receiver or in nodes near the receiver.

This is due to the fact that the receiver and aggregators in the vicinity of the receiver will receive more data compared to the SM sheet or aggregators near the leaf SM.

This will speed up the process of multiplying the SMS of the top level. 


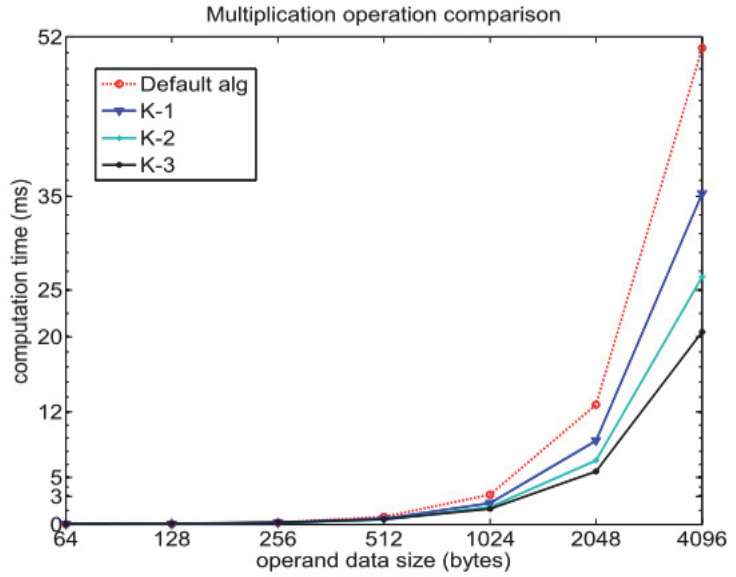

Fig. 8. Comparison of the Karatsuba algorithm calculation time and the default Java multiplication for ETE-H

\section{Conclusion}

This paper evaluated the effectiveness of widely recommended methods for data storing, which saves data using message size and ETE time delay indicators. Three approaches to data aggregation (combining finite homomorphic data (ETE-H), aggregation of hop-by-hop homomorphic data (HBH-A) and aggregation of hopby-hop (HBH-C) concatenation data were compared. Overall, the results showed that ETE-H provides a comparable ETE delay compared to HBH-A, which in itself does not provide confidentiality.

In addition, its performance is superior to $\mathrm{HBH}-\mathrm{C}$ in terms of ETE delay due to the stability of homomorphic multiplication compared to decoding at the receiver.

However, both ETE-H and HBH-C increase the size of the message that must be transmitted, and therefore their bandwidth requirements will be higher. As a result, ETE-H may be preferred solution if the main network traffic is not significant.

Otherwise, HBH-A can be chosen provided that it is supplemented with a separate privacy mechanism.

\section{References}

1. Zaballos A. Heterogeneous communication architecture for the smart grid [Electronic resource] / A. Zaballos, A. Vallejo, J. Selga // IEEE Network. - 2011. - № 25(5). - P. 30-37. https://doi.org/10.1109/mnet.2011.6033033.

2. The official site of ENERGY.GOV. Communications requirements of smart grid technologies. - Available at: http://surl.li/itap.

3. Lo C.-H. The Progressive Smart Grid System from Both Power and Communications Aspects / C.-H. Lo, N. Ansari // IEEE Communications Surveys \& Tutorials. - 2011. - № 14(3). - P. 799-821. https://doi.org/10.1109/surv.2011.072811.00089.

4. The official site of ENERGY.GOV. Smart Grid Vendor Ecosystem Report. - Available at: https://www.energy.gov/sites/prod/files/oeprod/DocumentsandMedia/2010_U.S._Smart_Grid_Vendor_Ecosystem_Report.pdf.

5. The official site of STANDARDS.IEEE. P802.11bb - Standard for Information Technology-Telecommunications and Information Exchange Between Systems Local and Metropolitan Area Networks-Specific Requirements - Part 11: Wireless LAN Medium Access Control (MAC) and Physical Layer (PHY) Specifications Amendment: Light Communications. - Available at: https://standards.ieee.org/project/802_11bb.html.

6. Akyildiz I.F. Cross-Layer Design in Wireless Mesh Networks / I.F. Akyildiz, W. Xudong // IEEE Transactions on Vehicular Technology. - 2008. - № 57(2). - P. 1061-1076. https://doi.org/10.1109/tvt.2007.911615.

7. Imboden T. Performance evaluation of wireless mesh networks using IEEE 802.11s and IEEE 802.11n / T. Imboden, K. Akkaya, Z. Moore // 2012 IEEE International Conference on Communications (ICC). - Ottawa, 10-15 June 2012. - P. 56755679. https://doi.org/10.1109/icc.2012.6364932.

8. Baker F. Rfc 6272 - internet protocols for the smart grid [Electronic resource] / F. Baker, D. Meyer. - Cisco Systems, 2011. - 66 p. - Available at: https://tools.ietf.org/html/rfc6272.

9. Leung K.C. Transmission control protocol (TCP) in wireless networks: issues, approaches, and challenges /

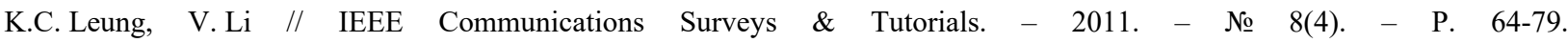
https://doi.org/10.1109/comst.2006.283822.

10. Benyamina D. Wireless Mesh Networks Design - A Survey / D. Benyamina, A. Hafid, M. Gendreau // IEEE Communications Surveys \& Tutorials. - 2012. - № 14(2). - P. 299-310. https://doi.org/10.1109/surv.2011.042711.00007.

11. Split- and Aggregated-Transmission Control Protocol (SA-TCP) for Smart Power Grid / T. Khalifa, A. Abdrabou, K. Naik, M. Alsabaan, A. Nayak, N. Goel // IEEE Transactions on Smart Grid. - 2013. - № 5(1). - P. 381-391. https://doi.org/10.1109/tsg.2013.2279756.

12. Standard Performance Evaluation Corporation 3GPP "General Packet Radio Access (GPRS) enhancements for Evolved Universal Terrestrial Radio Access Network (E-UTRAN) [Electronic resource]. - Available at: https://itectec.com/archive/3gppspecification-ts-23-401/.

13. Efthymiou C. Smart Grid Privacy via Anonymization of Smart Metering Data / C. Efthymiou, G. Kalogridis // First IEEE International Conference on Smart Grid Communications. - Gaithersburg, 4-6 October 2010. - P. 238243. https://doi.org/10.1109/smartgrid.2010.5622050.

14. Secure Lossless Aggregation for Smart Grid M2M Networks / A. Bartoli, J. Hernandez-Serrano, M. Soriano, M. Dohler, A. Kountouris, D. Barthel // First IEEE International Conference on Smart Grid Communications. - Gaithersburg, 4-6 October 2010. - P. 333-338. https://doi.org/10.1109/smartgrid.2010.5622063.

15. Fang X. On Karatsuba Multiplication Algorithm / X. Fang, L. Li. // The First International Symposium on Data, Privacy, and E-Commerce (ISDPE 2007). - Chengdu, 1-3 November 2007, P. 274-276. https://doi.org/10.1109/isdpe.2007.11. 


\section{Відомості про автора:}

\section{Hyx Taxa Haciф}

кандидат наук

завідувач кафедри

Університетського коледжу AL-Nukhba,

Багдад, Ірак,

https://orcid.org/0000-0001-9137-9914
Information about the author:

Nooh Taha Nasif

Doctor of Philosophy

Head of Department

of AL-Nukhba University College,

Baghdad, Iraq

https://orcid.org/0000-0001-9137-9914

\title{
МЕТОДИ АГРЕГАЦІї ДАНИХ ДЛЯ ЗНИЖЕННЯ ТРАФІКУ В КОМУТАЦІЙНИХ МЕРЕЖАХ SG ТА ЗАБЕЗПЕЧЕННЯ БЕЗПЕКИ ДАНИХ SG
}

\author{
Hyx Taxa Haciф
}

У статті оиінюється ефективність методів агрегаиії з використанням індикаторів розміру повідомленнь та часової затримки ЕTЕ. Розглянуто методи об'сднання кінщевих гомоморфних даних (ЕTЕ-H), поетапна агрегація гомоморфних даних (НBH-A) і поетапна конкатенація (HВН-C). Отримані результати показують, що ЕТЕ-Н забезпечує сорозмірну затримку ЕTЕ у порівнянні з НВН-А, який сам по собі не забезпечує конфіденційності. Крім того, його продуктивність перевершує НВН-С з точки зору затримки ЕТЕ, завдяки стабільності гомоморфного множення. Однак $i$ ETE-H, $i$ НВН-С збільшують розмір повідомлень,що передаються, внаслідок чого, вимоги до їх смуги пропускання будуть вищими. Зроблено висновок, щцо найбільш зручним є використання ЕТЕ-Н для умов, коли основний мережевий трафік не має значення. В іншому випадку можливе використання HBH-A за умови, щзо він буде доповнений окремим механізмом конфіденційності. Отримані результати дозволяють розщирювати існуючу інфраструктуру комунікацій SG для великого числа взаємопов'язаних систем з різноманітними можливостями і управлінням для надання послуг користувачам, а також інтелектуальних пристроїв при заданих вимогах безпеки.

Ключові слова: безпека в мережі, системи виявлення атак, аналіз трафіку.

\section{МЕТОДЫ АГРЕГАЦИИ ДАННЫХ ДЛЯ СНИЖЕНИЯ ТРАФИКА В КОММУТАЦИОННЫХ СЕТЯХ SG И ОБЕСПЕЧЕНИЯ БЕЗОПАСНОСТИ ДАННЫХ SG}

\author{
Нух Таха Насиф
}

В статье оценивается эффективность иироко рекомендуемых методов агрегации с использованием индикаторов размера сообщения и временной задержки ETE. Рассмотрены методы объединения конечных гомоморфных данных (ETE-H), поэтапная агрегаиия гомоморфных данных (НВН-A) и поэтапная конкатеначия (НВН-С). Полученные результаты показывают, что ЕTЕ-Н обеспечивает сопоставимую задержку ЕТЕ по сравнению с НВН-А, который сам по себе не обеспечивает конфиденциальности. Кроме того, его производительность превосходит НВН-С с точки зрения задержки ЕTЕ из-за стабильности гомоморфного умножения. Однако и ЕTE-H, и НВН-С увеличивают размер передаваемых сообщений, и, следовательно, требования к их полосе пропускания будут выше. Таким образом, сделан вывод о предпочтительном использовании ЕТЕ-Н для условий, когда основной сетевой трафик не имеет значения. В противном случае возможно использование НВН-А при условии, что он будет дополнен отдельным механизмом конфиденциальности. Полученные результаты позволяют расширять существуюшую инфраструктуру коммуникачий SG для большого числа взаимосвязанных систем с разнообразными возможностями и управлением для предоставления сквозных услуг пользователям, а также интеллектуальных устройств, при заданных требованиях безопасности.

Ключевые слова: безопасность в сети, системы обнаружения атак, анализ трафика. 